\title{
Evaluation of Mechanical Properties of Sisal/Glass Fiber Reinforced Epoxy Composites
}

\author{
Suresh Kumar. $\mathrm{D}^{1}$ Dr. Sanjeevamurthy ${ }^{2}$ Dr. G. Mallesh ${ }^{3}$ \\ ${ }^{1}$ Assistant Professor, Department of Mechanical Engineering, Government Engineering College, Hassan - 563201, Karnataka \\ ${ }^{2}$ Professor, Department of Mechanical Engineering, Sri Siddhartha Institute of Technology, Tumkur - 572105, Karnataka, India \\ ${ }^{3}$ Professor, Department of Mechanical Engineering, Sri Jayachamarajendra College Engineering, Mysore-570 006, Karnataka,
}

\begin{abstract}
Composite materials are the combination of two are more materials which are different in form and chemical composition, these are gaining more importance as structural materials in present day engineering design and development activities because they offer very attractive mechanical properties such as high strength to weight ratio, higher thermal and corrosive resistance. these are composed of fibers, matrix and fillers commonly used fibers are Glass, Aramid, Kevlar and Carbon, matrix materials are epoxy resins, phenolic resins, unsaturated polyester and polyurethane etc., Fillers are particulates which are added to the material to enhance the desired properties.

Major problem associated with urbanization and industrialization is pollution but industrialization is necessity to boost the economy of the developing countries. Urbanization leads to the environmental pollution due the generation of huge amount of solid wastes. Due to increased environmental awareness and consciousness throughout the world has developed an increasing interest in natural fibers, fillers and its applications in various fields of engineering. Therefore, in this paper attempts are made to develop natural and biodegradable FRP composite using sisal/glass reinforced with epoxy resin to study the mechanical properties.
\end{abstract}

Keywords-Sisal Fiber, Epoxy resign, Coconut shell powder, Natural and biodegradable FRP composites Mechanical properties.

\section{INTRODUCTION}

Composites are the amalgamation of two or more materials which are different in form and chemical constituents. These are gradually gaining more significance as structural materials in the preset day engineering design and development activity; this is because they offer very attractive physical-mechanical properties such as high strength to weight ratio, higher thermal, corrosive and wear resistance. Hence these materials have the potential to replace the conventional materials to manufacture automobile, aircraft, marine components, wind turbine blades, heat insulators, sporting equipment etc.

Composite materials can be classified based on the geometry of reinforcing materials which are responsible for the performance of the composites. These are classified shown in Figure.1.

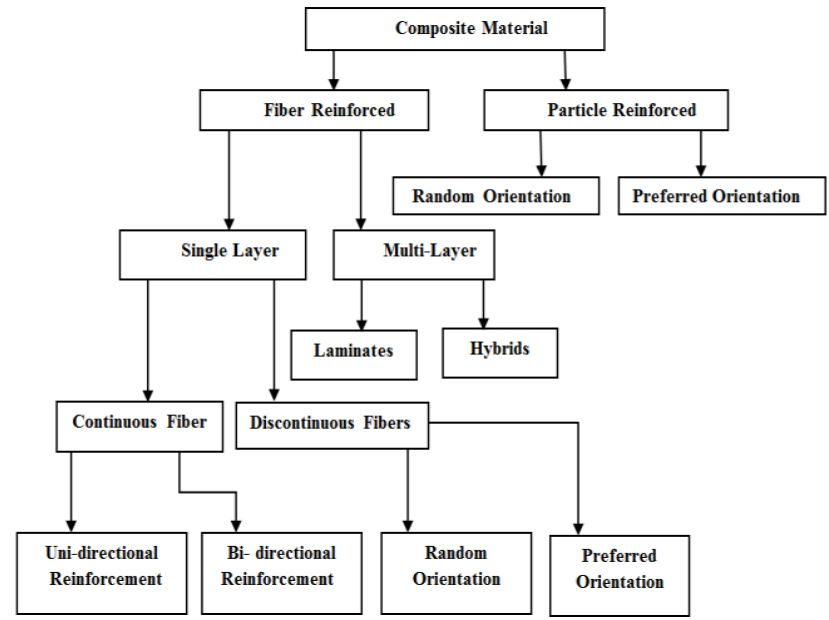

Figure 1. Classification of Composites Materials

Natural fibers are drawn from various parts of the plants such as bast or stem, leaf, seed, fruit, wood and grass. Flax, Hemp, Jute, Kenaf, Roselle, Ramie fibers are derived from the plants stem. Abaca, Banana, Cantala, Caroa, Curaua, Date palm, Henequen, Pineapple, Sisal fibers are extracted from the plant leaves. Cotton fibers are developed using seeds and Coir, Kapok, Oil palm, Sponge gourd fibers are derived from the fruits of the plants. Bagasse, Bamboo fibers were drawn from the grass. In the present scenario due growing interest on the natural fibers, these fibers are extensively used in the development of composite materials for industrial applications and fundamental research. Hence, in the present research attempts are made to develop sisal/glass reinforced with epoxy resin to study the mechanical properties.

\section{LITERATURE REVIEW}

A literature survey is the sources of background information relevant to a particular area of research. It provides methodologies, description and critical assessment of each work. Present research is mainly focused on the development of natural fibers FRP composites to study the mechanical behaviour.

Bernd Wetzela.et.al, [1] were studied the behaviors of micro- and Nano-scale particles of $\mathrm{CaSiO}_{3}$ and $\mathrm{Al}_{2} \mathrm{O}_{3}$ as a fillers used as reinforcements in glass epoxy resin. It is found that mechanical properties and synergistic effects were improved. Wear resistance and stiffness effects are explained in terms of reinforcing mechanisms. 
Kazuya Okubo.et.al, [2] were developed eco-friendly composites using bamboo fibers to study their mechanical property. A comparative result indicates that the bamboo fibers has strength equivalent to that of conventional glass fibers. Due decrease of voids and well impregnation of fibers the tensile strength of steam exploded fibers increases about $\quad 15-30 \%$ as compared to that of mechanically extracted fibers.

Feng-Hua Su.et.al, [3] fabricated pure and filled Nomex material composites to study the wear and friction behaviors using pin-on- AISI-1045 steel disk experiments. Further, wear behaviors of worn out surfaces of both pure and filled Nomex material composites were studied using SEM analyses. The tensile and adhesive strength of the reinforced and unreinforced composites with PFW (polyfluo150 wax) or nano $\mathrm{SiO}_{2}$ were evaluated. It is observed that wear resistance was enhanced with decrease in friction coefficient due to the addition of PFW and Nano $\mathrm{SiO}_{2}$.

X.F. Yao.et.al, [4] $\mathrm{SiO}_{2}$ /epoxy Nano composite were fabricated to study the crack propagation path and fractured surface behavior using field emission SEM and SEM respectively to analyze the distribution of $\mathrm{SiO}_{2}$ particles. It noticed that these particles were uniformly distributed and observed that cup and cone fracture failure was formed on the tested specimens.

Manoj Singlal.et.al, [5] 10 X 10 X10 mm fiber- glass epoxy composites were manufactured to study the shock waves in naval ship structure in sea mines and noticed that explosion produce underwater severe shock loads and similar analysis was carried out for different weight fractions of glass fibers with epoxy resin \& fly ash filled composites and observed that filled composites have less impact on explosion.

C.M. Manjunatha.et.al, [6] polymer composites fabricated using glass fiber with $10 \mathrm{wt} \%$ of silica nano particles to study the fatigue life. It was found that fatigue life increases by two to three times with the addition of silca particles. Tensile fatigue tests were conducted and identified that there is suppressed cracking in the matrix intern reduces crack propagation rate in the nano particle modified composite system.

M. Lai.et.al, [7] thermal and mechanical properties of rubber micro-fillers and $\mathrm{SiO}_{2}$ nano particles filled epoxy composite were estimated to know the effect of fillers in the composite. The results indicate that the inclusion of $\mathrm{SiO}_{2}$ nano particles tensile modulus enhances and reduces with the addition of rubber content. During the investigations on variation of temperature, addition of particles content has no effect on the coefficient of thermal expansion. The effect of the rubber content that introduces a strong relief during processing when residual strains are generated, whereas silica content tends to increase their level.

Sandhyarani Biswas.et.al, [8] fabricated bamboo fiber reinforced epoxy composites with $\mathrm{Al}_{2} \mathrm{O}_{3}, \mathrm{SiC}$ and industrial wastes such as copper slag and red mud fillers are used to study the synergistic effects. Result showed that the tensile strength of particulate filled bamboo epoxy composites are found to be declining in most of the cases because these composite systems contains voids, it also is noticed minimum void fraction was found in red mud filled composites as compared to $\mathrm{SiC}$.

Dr.G. Ramachandra Reddy.et.al, [9] determine the mechanical performance for the different weight fractions of filler with Epoxy composites filled with Sansevieria cylindrical was hybridized with betel nut short fiber with using the hot press moulding and extrusion process. It is observed that $90 \%$ Epoxy resin:10\% Betel nut composites established the better performance compared with other composites.

Goulart.et.al, [10] mechanical properties of natural fiber and glass fiber composites were studied and observed that certain drawbacks in natural fibers such as formation aggregates, incompatibility during processing of polymer matrix and weak resistance to moisture, to improve fibers and matrix compatibility various treatments and modifications are being used, such as acetylating, bleaching and use coupling agent and so on due to these reasons use of natural fibers in composite reduced. In this study effect of various treatments are studied to the possible use of natural fibers.

Sandeep Kumar.et.al, [11] Studied on the erosive behavior of fiber reinforced hybrid composites consisting of vinyl ester resin and short E-glass/carbon fiber at different fiber weight fractions. Investigation of control factors using Taguchi orthogonal arrays design that lead to minimization of erosive rate with respect to impact velocity, impingement angle, and size of erodent by keeping other factors constant. The mechanical properties were evaluated to determine possible correlation with erosion rate of these composites. The storage modulus steadily increases up to $3927 \mathrm{MPa}$ for $40 \mathrm{wt}$. \% fibers, but on further increase in the fiber content, the value decrease to $3321 \mathrm{MPa}$ at $0^{\circ} \mathrm{C}$.

Ch. Ramesh.et.al, [12] fabricated epoxy matrix composites filled with different weight fractions of slag particulate by hand layup method and to evaluate the mechanical properties it is noticed from the results that flexural and tensile properties enhanced by $20 \%$ beyond that Impact properties gradually reduces. If slag and cement are used as filler the mechanical behavior were improved.

WasimAkram.et.al, [13] studied the mechanical properties of glass epoxy composite materials filled with $\mathrm{Al}_{2} \mathrm{O}_{3}$, $\mathrm{CaCo}_{3}, \mathrm{SiO}_{2}$ and $\mathrm{PbO}$ are the fillers, with the addition of these fillers mechanical properties were improved and also noticed that lead oxide filler has a good tensile strength, Silica Oxide has a better torsional and hardness properties as compared to others fillers

TimoJ.Lehtonenn.et.al, [14] In vitro degradation testing was carried out by exposing the glass fibers to SBF and TRIS at $37.1^{\circ} \mathrm{c}$ for a period of 182 days to investigate the dissolution behavior of restorable glasses manufactured with silica based fibers and observed that all fibers showed continuous resorption throughout the study. Further fibers are fibers exposed to bioactivity by forming a layer calcium phosphate and noticed that absorption behaviors of coated fiber are minimum.

R. Satheesh Raja.et.al, [15] Fly ash filled epoxy polymer composites are manufactured with different fly ash particle sizes to investigate the physical and mechanical properties. 
It is observed that properties were enhanced with increase in the size of particles and overall strength of the composite decrease with increase in particle size.

C.Chaithanyan.et.al, [16] 40 and 50\% volume fractions of sisal and coir natural fibers are used in polyester resin to manufacture composites using hand layup process to estimate the mechanical properties. The results revealed that sisal-glass composite has better tensile strength compared to coir-glass composites. Further hybrid composites were developed to estimate the flexural and impact strength observed hybrid composites have better strength.

Sudeep Deshpande.et, al, [17] 15\% volume fraction of bone and coconut shell powder filled E-glass /jute fiber reinforced epoxy composites were fabricated to investigate the mechanical properties in comparison with HFRP composites. With the addition of CSP flexural, inter laminar shear and tensile modulus were enhanced. There was increase in hardness and impact strength due the addition of bone powder.

RafahA.Nasif.et.al, [18] $\quad \mathrm{TiO}_{2}, \quad \mathrm{Al}_{2} \mathrm{O}_{3}$ ceramics and industrial wastes filled glass fiber reinforced epoxy composite material were developed to study the mechanical properties and found that $\mathrm{TiO}_{2}$ filled composite has lowest tensile and highest impact strength as compared to other filled composites. Hardness test results revealed that $\mathrm{Al}_{2} \mathrm{O}_{3}$ filled composites have less hardness compared to that of hybrid composites.

Ramesh K. Nayak.et.al, [19] hand lay-up technique is used to manufacture glass fiber/epoxy composite filled with different weight fractions of $\mathrm{Al}_{2} \mathrm{O}_{3}, \mathrm{SiO}_{2}$ and $\mathrm{TiO}_{2}$ micro particles to evaluate mechanical behavior. Flexural strength, flexural modulus and ILSS increases as the particle size of $\mathrm{SiO}_{2}$ decreases compared with other micro particles. Further, hardness and impact energy were increased as the particle size of $\mathrm{Al}_{2} \mathrm{O}_{3}$ increases.

From the available literature it is observed that many researchers have attempted to develop and study mechanical properties of FRP composites and limited work has been done using natural fibers. Hence in this research work attempts are made to develop Sisal/ glass epoxy composites study the mechanical behavior.

\section{MATERIALS AND METHODS}

\section{A. Reinforcing Fibers}

The base of the composite is fiber. It is often called reinforcing material. A strength of composite is mainly depending upon the nature of reinforcing fibers. There is a broad classification of reinforcing fibers but mainly they are classified according to their origin i.e. synthetic or natural fibers. They are available in different forms such as woven, non-woven or randomly oriented in more than one direction.

\section{B. Synthetic Fibers}

Synthetic fabrics are man-made fibers rather than natural fibers. Synthetic fibers are made by joining monomers into polymers, using polymerization process. There are varieties of synthetic fibers used for different applications such as Glass, Aramid, Kevlar, Carbon, Nylon etc., are popular for load bearing applications.

Selection of the different types of fibers, volume fraction, orientation and length of the fibers are very important parameters which influences the following characteristics of composite materials

- Density

- Tensile modulus and strength

- Compressive modulus and strength

- Fatigue strength and fatigue life failure mechanisms

- Impact and hardness strength

- Service life

- Thermal and electrical properties

- Cost

\section{Natural Fibers}

To substitute synthetic fibers, Natural fibers are extensively used in present day engineering applications due to their positive characteristics such as low density, high specific strength, stiffness, biodegradability and renewability. Table 3.2 shows the physical and mechanical properties of natural fibers extensively used in the manufacture of FRP composites.

TABLE I.

PHYSICAL AND MECHANICAL PROPERTIES OF NATURAL FIBERS

\begin{tabular}{|c|c|c|c|c|}
\hline Fibers & $\begin{array}{c}\text { Tensile } \\
\text { Strength (MPa) }\end{array}$ & $\begin{array}{c}\text { Young's } \\
\text { modulus (GPa) }\end{array}$ & $\begin{array}{c}\text { Elongation at } \\
\text { break (\%) }\end{array}$ & $\begin{array}{c}\text { Density } \\
\left(\mathrm{gm} / \mathrm{cm}^{3}\right)\end{array}$ \\
\hline Bamboo & 290 & 17 & - & 1.25 \\
\hline Banana & $529-914$ & $27-32$ & 5.9 & 1.35 \\
\hline Cotton & 400 & 12 & $3-10$ & 1.51 \\
\hline Hemp & 690 & 70 & 1.6 & 1.48 \\
\hline Jute & $510-710$ & 26.5 & 1.6 & 1.40 \\
\hline Palm & 340 & 3.8 & 12 & 1.30 \\
\hline Sisal & $610-820$ & $9-22$ & $2-3$ & 1.34 \\
\hline E-glass & 2400 & 73 & 3.0 & 2.55 \\
\hline
\end{tabular}

It is noticed from the literature that among all the natural fibers, sisal fibers have more advantages in contrasting with better tensile strength, maximum load carrying capacity, exceptionally durable, low maintenance with minimal wear and tear. Presently, sisal fibers are utilized as an environment friendly strengthening agent to substitute asbestos and fiberglass in polymer composite materials for various applications including the automotive, marine and construction industries.

Sisal is a natural fiber (scientific name Agave sisalana) of Agavaceae (Agave) family which is traditionally used in making twine and ropes. Sisal is a member of the cactus family. Sisal plant comprise of a rosette of sword-shaped leaves about 1.5 to 2 meters in length. A sisal plant harvests around 200 to 250 leaves and every single leaf contains 1000 to 1200 fibers. Fibers are generally treated with appropriate chemical treatment before it is being used. The chemical treatment modifies the fiber surface properties, which enhances interfacial adhesion between the fiber and the matrix, improves mechanical properties. 
Hence, in this research work alkali treated plain woven sisal fabric was chosen to fabricate Glass/Sisal hybrid composites. Further, in this work to achieve uniform distribution, to minimize the void formation and to get uniform thickness of laminates, fibers in plain woven fabric form supplied by Sri Lakshmi Group Exports and Imports, Guntur, Andhra Pradesh, India was used.

\section{Matrix Materials}

The roles of the matrix in a fiber-reinforced composite is to keep the fibers in place, transfer stresses between the fibers, provide a barrier against an adverse environment, such as chemicals and moisture, and to protect the surface of the fibers from mechanical degradation. The matrix plays a minor role in the tensile load carrying capacity of a composite structure. However, selection of a matrix has a major influence on the compressive; inter laminar shear as well as in-plane shear properties.

In general, thermoset and thermoplastic matrix materials are available for FRP composite. Epoxy, polyester, phenol - formaldehyde and vinyl esters are the commonly used thermoset resins in various structural composites. Epoxy, polyesters and other resins in liquid form contain monomers, which convert into polymers when the resin is cured. The resulting solid is called thermoset which is tough, hard, insoluble and infusible. Epoxy and Polyesters are extensively used in numerous industrial applications because of their superior mechanical and electrical properties, excellent heat resistance and better adhesion properties.

Hence in this research work epoxy resin was used in the fabrication of Glass/Sisal fiber reinforced hybrid composite because of their versatility, excellent adhesive properties, low shrinkage and low cost. Epoxy resin Araldite LY556 of density $1.2 \mathrm{gm} / \mathrm{cc}$ is used in the preparation of matrix system in a ratio of 10:1.

\section{E. Fabrication techniques of FRP Composite}

In the present work a composite sheet of $400 \times 400 \times 3 \mathrm{~mm}$ thick plates are fabricated using hand layup and bag molding process. The different stages of the fabrication process are as shown in Figure 2. Initially number of layers of the Sisal/glass fibers is marked and cut as per the required dimensions from the Sisal/glass mat strands with the help of marker and scissors, number of layers are chosen based on the thickness of the laminate. In the next step calculated amount of matrix resin along with hardener is mixed and first layer of the Sisal/glass fiber are placed on a flat surface which is cleaned with the help of acetone. First layer is coated with a layer of resin either through a spray gun, or through a brush. Similar procedure will be followed till to get the required thickness of a laminate. In order to remove the excess mixture, perforated sheet and breather sheet are placed on to the surface of the glass fiber. Vacuum pressure is created in the composite system about $1 \mathrm{hr} 30 \mathrm{~min}$ in order to remove the air bubbles and excess resin in between the layers. Curing of the composite system is carried out for an hour at $100^{\circ} \mathrm{C}$.

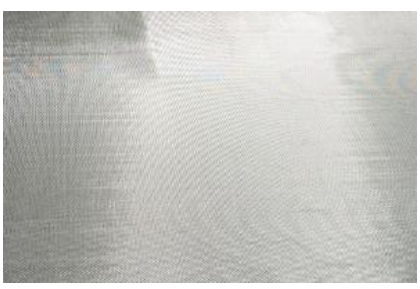

Glass fiber

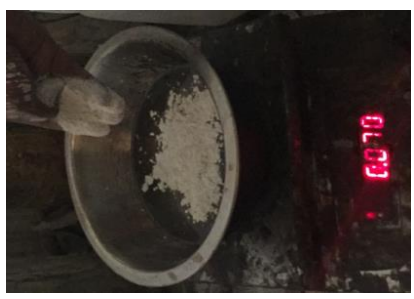

Weighing of mixture

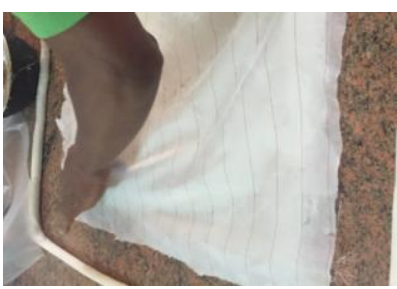

Covering the glass fiber

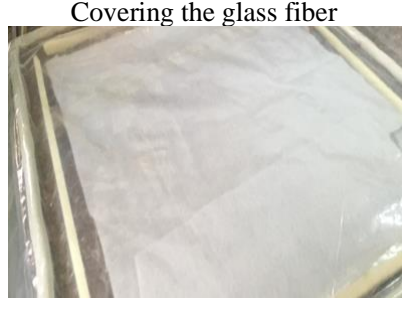

Composite with polymer sheet
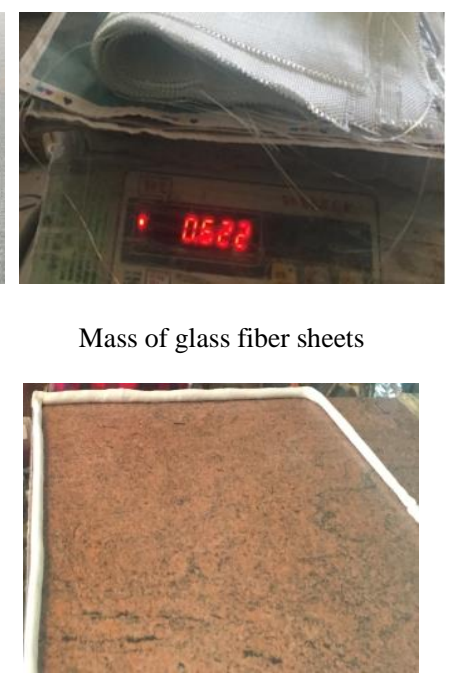

Flat surface
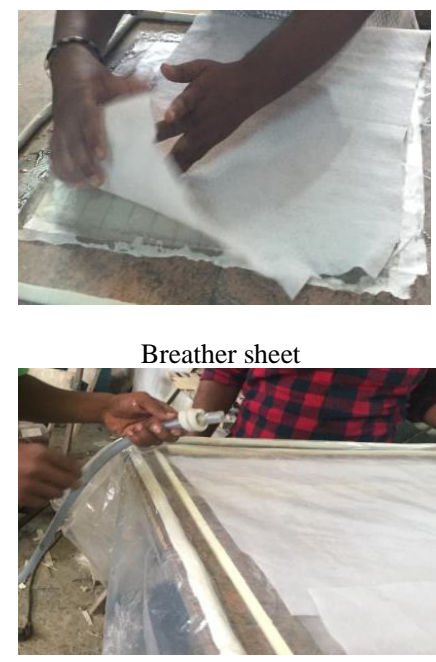

Vacuum bag
Mass of glass fiber sheets

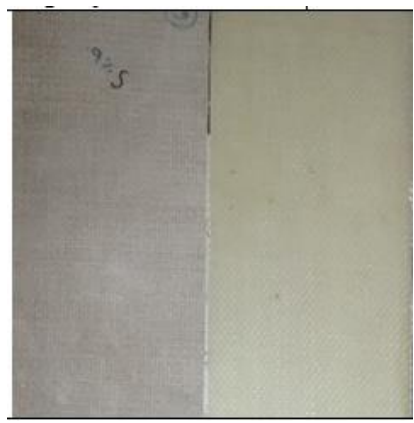

Sisal and Glass sheets

Figure 2. Fabrication Process of FRP Composite

\section{F. Specimen preparation}

After the fabrication of composite, laminates were cut using band knife cutting machine as shown in Figure 3. This machine works similar to saw mill technique, blade moving vertically through a flat working table, by moving the laminates the specimen as per ASTM standards. 


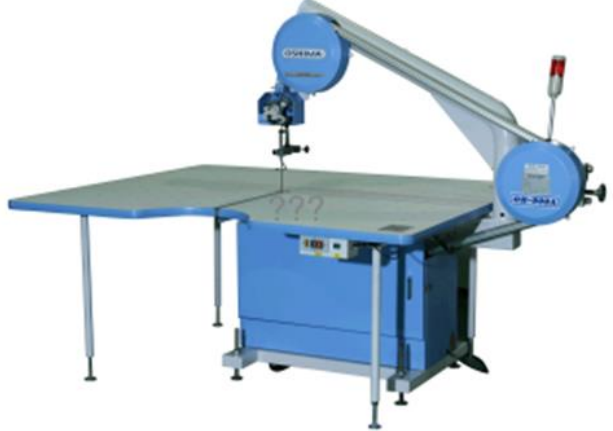

Figure 3. Band knife cutting machine

\section{RESULTS AND DISCUSSIONS}

Physical and mechanical properties of Glass/ SisalEpoxy reinforced composites were evaluated as per the ASTM standards. The test results of various properties are reported and discussed in this section.

\section{A. Density and Void Fraction}

The theoretical and experimental densities and void fraction of the composites were calculated and observed that maximum void present is $1.753 \%$ which indicates a better bonding between fiber and matrix at the interface regions.

TABLE II

DENSITY AND VOID FRACTION OF GLASS/SISAL EPOXY COMPOSITES

\begin{tabular}{|c|c|c|c|}
\hline Laminates & $\begin{array}{c}\text { Theoretical } \\
\text { density } \\
(\mathrm{gm} / \mathrm{cc})\end{array}$ & $\begin{array}{c}\text { Experimental } \\
\text { density } \\
(\mathrm{gm} / \mathrm{cc})\end{array}$ & $\begin{array}{c}\text { Void } \\
\text { fraction } \\
(\%)\end{array}$ \\
\hline Glass-Epoxy & 1.4972 & 1.4961 & 0.073 \\
\hline Sisal-Epoxy & 1.2375 & 1.2158 & 1.753 \\
\hline
\end{tabular}

It is evident from the Table II that Sisal/Epoxy contains more voids than Glass/Epoxy composite system fiber. This is due to the fact that sisal fibers comprise of lumens in its cellular structure which acts as void.

\section{B. Tensile Strength}

The tensile properties Glass/Sisal-Epoxy were estimated using computerized universal testing machine and six tests were conducted based on the results average peak load and ultimate tensile strength was estimated and represented in the bar graph shown in Figure 4 and Figure 5.

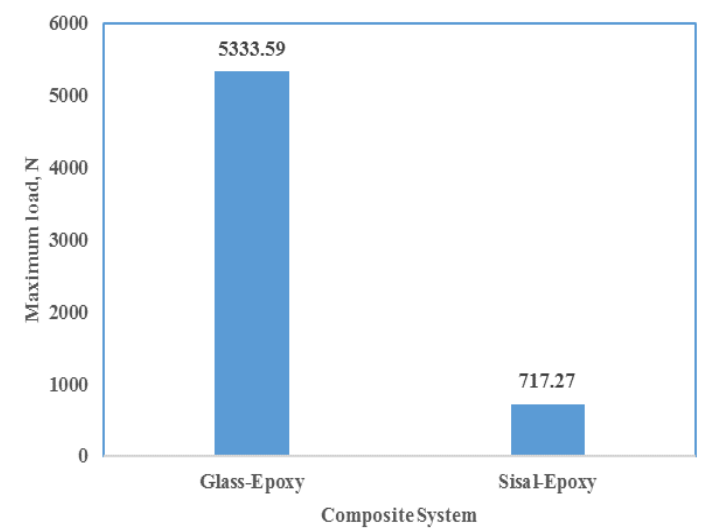

Figure 4. Maximum load carrying capacity of composite laminates

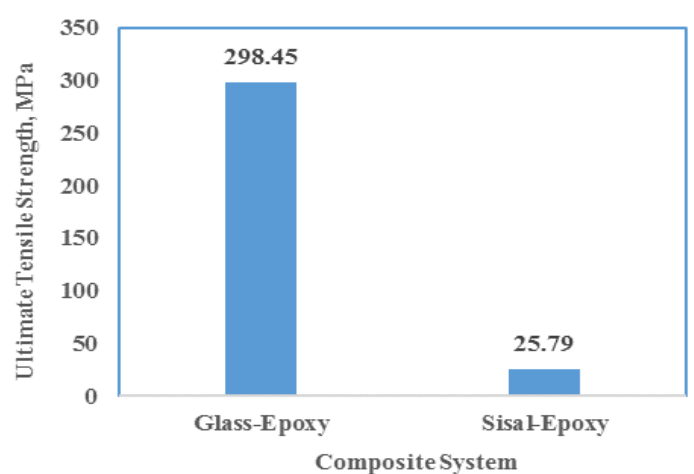

Figure 5. Ultimate tensile strength of composite laminates

It is observed from the results that Glass-Epoxy composite laminate exhibits better tensile strength and maximum load carrying capacity as compared Sisal-Epoxy composite. Enhancement of tensile strength in Glass-Epoxy is due to better bonding, adhesion and uniform dispersion of the fiber in the matrix and Sisal-Epoxy exhibits lower tensile strength and load carrying capacity due to the presence of pores at the interface between the fiber and the matrix and the weak interfacial adhesion.

\section{Flexure Strength}

To analyze the flexural properties of the composite laminates flexural tests were conducted as per ASTM standard.

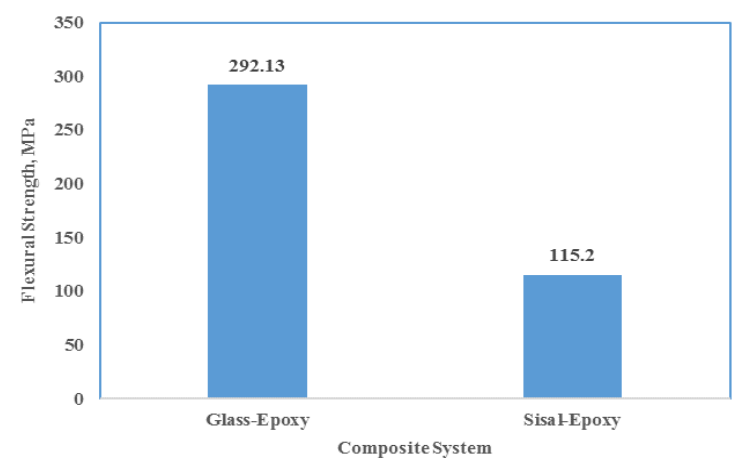

Figure 6. Flexural strength of composite laminates

Figure 6 depict the flexural strength Glass-Epoxy and Sisal-Epoxy composite it is evident that Glass-Epoxy laminate exhibits higher flexural strength as compared to Sisal-Epoxy laminates. This is due the better bonding, and improved adhesion between fiber matrix interface.

\section{Inter-Laminar Shear Strength (ILSS)}

Inter-laminar shear strength (ILSS) is an important property for the composite laminates as the failure occurs more often at the inter-laminar region of such composite. The presence of porosity and voids will have detrimental effect on the matrix dominated properties like bending strength, compressive strength and Inter-laminar shear strength. To analyse the flexural properties of the composite laminates flexural tests were conducted as per ASTM standard. It is noticed that Glass-Epoxy composite laminate exhibits better inter laminar shear strength compared to Sisal-Epoxy it is attributed that better 
bonding, and improved adhesion between fiber and matrix interface in Glass-Epoxy. Poor dispersion, presence of voids content intern leads to lower ILLS (Figure 7).

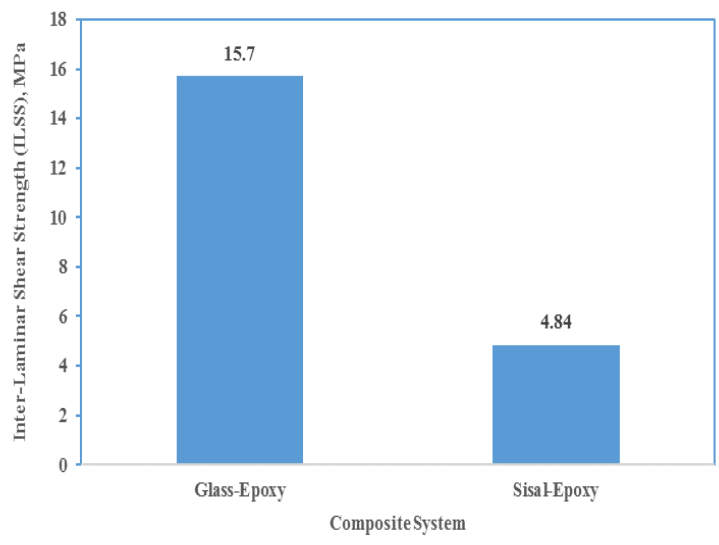

Figure 7. Inter laminar shear strength of composite laminates

Similarly, micro hardness, impact strength of Glass-Epoxy composite laminate exhibits improved characteristics in comparison with Sisal- Epoxy composites and presence of voids in Sisal- Epoxy composites leads to more water absorption.

\section{CONCLUSIONS}

- Development of hybrid composite using natural (Sisal) fibers along with synthetic (glass) fibers enhances mechanical properties, biodegradability and ease of disposal at the end of their service life.

- It is evident from the experiments that the composite laminates fabricated with glass fabric in outer layer leads to minimum moisture absorption characteristics. Hence, the developed hybrid composite laminates will be best suited for boat hulls and other water engineering applications.

- Sisal-Glass fiber reinforced hybrid composites can be extensively used in the application where bending load is important.

\section{REFERENCES}

[1] Bowman, M., Debray, S. K., and Peterson, L. L. 1993. Reasoning about naming systems. Bernd Wetzela, Frank Hauperta, Ming Qiu Zhangb "Epoxy Nano composites with high mechanical and Tribological performance" Composites Science and Technology 63 (2003) 2055-2067.

[2] Kazuya Okubo, Toru Fujii, Yuzo Yamamoto"Development of bamboo-based polymer composites and their mechanical properties" K. Okubo et al. / Composites: Part A 35 (2004) 377-383378.

[3] Feng-Hua Su, Zhao-Zhu Zhang, Wei-Min Liu "Tribological and mechanical properties of Nomex fabric composites filled with polyfluo 150 wax and nano-SiO2" Composites Science and Technology 67 (2007) 102-110.

[4] X.F. Yao, D. Zhou, H.Y. Yehb "Macro/microscopic fracture characterizations of $\mathrm{SiO} 2 /$ epoxy Nano composites" Aerospace Science and Technology 12 (2008) 223-230.

[5] Manoj Singlal, Vikas Chawla "Mechanical Properties of Epoxy Resin - Fly Ash Composite" Vol. 9, No.3, pp.199-210, 2010.

[6] C.M. Manjunatha, A.C. Taylor, A.J. Kinloch, S. Sprenger "The tensile fatigue behaviour of a silica nanoparticle-modified glass fibre reinforced epoxy composite" Composites Science and Technology 70 (2010) 193-199.

[7] M. Lai, K. Friedrich, J. Botsis, T. Burkhart "Evaluation of residua strains in epoxy with different Nano/micro-fillers using Embedded fiber Bragg grating sensor" Composites Science and Technology 70 (2010) 2168-2175.

[8] Sandhyarani Biswas, Alok Satapathy Amar Patnaik "Effect of Ceramic Fillers on Mechanical Properties of Bamboo Fiber Reinforced Epoxy Composites: A Comparative Study" Advanced Materials Research Vols. 123-125 (2010) pp 1031-1034.

[9] Dr.G. Ramachandra Reddy, Dr.M. Ashok Kumar, K.V.P.Chakradhar "Fabrication and performance of hybrid Betel nut (Areca catechu) short fibre/ Sansevieria cylindrical (Agavaceae) epoxy composites" International Journal of Materials and Biomaterials Applications 2011; 1 (1): 6-13.

[10] Goulart, S.A.S, Oliveira, T.A. Teixeira, Miléo, P.C. Mulinari, D. R. "Mechanical Behaviour of Polypropylene Reinforced Palm Fibers Composites" Procedia Engineering 10 (2011) 2034-2039.

[11] Sandeep Kumar, Bhabani K. Satapathy , Amar Patnaik "Thermo mechanical correlations to erosion performance of short glass/carbon fiber reinforced vinyl ester resin hybrid composites"Computational Materials Science 60 (2012) 250-260.

[12] Ch.Ramesh , N.Jeevan Kumar, Malaga.Anil Kumar "Fabrication and Mechanical Properties of Iron Slag Matrix Composite Materials" International Journal of Engineering Research and Development eISSN: 2278-067X, Volume 5, Issue 4 (December 2012), PP. 34-46.

[13] Wasim Akram, Sachin Kumar Chaturvedi, Syed Mazhar Ali "Comparative Study of Mechanical Properties of E-Glass/Epoxy Composite Materials with $\mathrm{Al}_{2} \mathrm{O}_{3}, \mathrm{CaCo}_{3}, \mathrm{SiO}_{2}$ and PBO Fillers" International Journal of Engineering Research \& Technology Vol. 2 Issue 7, July - 2013 ISSN: 2278-0181.

[14] TimoJ. Lehtonenn, Jukka U.Tuominen,Elina Hiekkanen "Dissolution behaviour of high strength bioresorbable glass fibres manufactured by continuous fibre drawing" journal of the mechanical behaviour of biomedical materials 20 ( 2013 ) 376 -386.

[15] R.Satheesh Raja, K.Manisekar , V.Manikandan "Effect of fly ash filler size on mechanical properties of polymer matrix composites" International Journal of Mining, Metallurgy \& Mechanical Engineering (IJMMME) Volume 1, Issue 1 (2013) ISSN 23204060 .

[16] C.Chaithanyan, H.Venkatasubramanian, Dr. S.Raghuraman, T Panneerselvam "Evaluation of Mechanical Properties of CoirSisal Reinforced Hybrid Composites Using Isophthalic Polyester Resin" IJIRSET Vol. 2, Issue 12, December 2013.

[17] Sudeep Deshpande, T Rangaswamy "Effect of Fillers on EGlass/Jute Fiber Reinforced Epoxy Composites" Journal of Engineering Research and Applications ISSN: 2248-9622, Vol. 4 Issue 8(Version 5), August 2014, pp.118-123.

[18] RafahA.Nasif "Study the Effect of Fillers on the Glass Fiber Reinforced Composites" Engineering \& Technology. Journal, Vol 32, Part(B), No.1,2014.

[19] Ramesh K. Nayak, Alina Dash and B.C.Ray "Effect of epoxy modifiers (A12O3/SiO2/TiO2) on mechanical performance of epoxy/glass fiber hybrid composites" Procedia Materials Science 6 ( 2014 ) $1359-1364$. 